\title{
Changing Welfare States and the "Sandwich Generation":
}

\section{Increasing Burden for the Next Generation?}

\author{
BY HARALD KÜNEMUND
}

\begin{abstract}
The burden placed on individuals aged 40 to 59 - especially on women by competing demands from work and both older and younger family members is often addressed using the metaphor of the "sandwich generation". Based on a systematization of the definitions used in the literature, empirical evidence on the frequency of such generational constellations and on their impact on the well-being of sandwiched adults will be presented. Analysing the second wave of the German Aging Survey shows that being sandwiched - defined as a generational constellation is very common, but simultaneous care activities for both older and younger family members are rare, especially in combination with labour force participation, and that life satisfaction is not systematically related to being sandwiched. Implications for further research and future developments will be discussed, especially with respect to changes in family structure (e.g. the beanpole family) and changes in the amount of welfare state spending for the aged.
\end{abstract}

Keywords: Sandwich generation, Caregiver, Midlife, Intergenerational relations. 


\section{Introduction}

The aging of societies is a major challenge of the next decades. The increases in numbers and proportions of elderly people and in life expectancy have tremendous consequences, especially with respect to public pension and health care systems. Most countries have implemented reforms to reduce the welfare state spending on the elderly in the near future. In addition to reduced pension entitlements due to unsteady careers, these measures will most probably result in less economic resources and greater social inequality within future cohorts of elderly people. However, with regard to personal care for the elderly, the situation seems even worse: the decreasing number of children of the "baby boomers" and the growing childlessness within these cohorts result in a lack of potential caregivers - namely, daughters of these future elderly -, and the increasing number of singles in their children's generation may result in an additional lack of daughters-in-law. Furthermore, these women are increasingly participating in the labour force and are geographically mobile. In this view, reducing the welfare state spending on the elderly may aggravate the burden placed on the daughters of the baby boom cohorts, as they are less likely to share care activities with siblings and as they face competing demands from both younger and elderly kin as well as from the labour market.

The metaphor of the "sandwich generation" - along with similar terms like "women in the middle" or "being caught in the middle" - is commonly used to describe this specific burden placed on women aged 40 to 59 by competing demands from work and both older and younger family members. ${ }^{1}$ This paper asks about the empirical relevance of the metaphor: is this a common situation; is role-overload and overburden a

1 In the discussion of the sandwich generation, the term "generation" refers to the generational position within the family, the middle age group. This generational membership changes over life (from grandchild to grandparent). Therefore, in this paper, the term generation does not refer to other meanings like birth cohort, political generation, or welfare generation. 
typical experience in such generational constellations; will these situations become more relevant in the future, as is suggested by the majority of the literature? To answer these questions, I will briefly review the international literature and discuss the empirical evidence of the sandwich generation (2), present data for Germany (3) along with descriptive and multivariate analyses of the subject according to the conclusions drawn from the literature review (4). Finally, I briefly discuss future prospects of this constellation and the possible impact of changes in the welfare systems (5).

\section{Literature review}

The consequences of being sandwiched have been described and illustrated most often using qualitative data and methods (for example, Brody 1990) or analysing small samples of women in the sandwich situation (for example, Nichols \& Junk 1997). These studies - as well as a growing body of advisory literature (for example, Zal 1992; Roots 1998) - point out the relevance of the sandwich position and the often heavy load it imposes on individuals. However, this literature does not provide reliable information on the proportion of sandwiched adults. Speaking of a "generation" seems to imply that this pattern is valid for large groups ideally, for all members of the age group (with parents and children) but in most of these cases the empirical arguments do not take into account the cumulation of these roles or activities. Only singular facts like the increase of the very old population - "people (...) have more parents, grandparents, and great-grandparents than has ever been true before" (Brody 1981: 473) - and the increase in labour force participation by women - "the majority of middle-aged women (the principal caregivers to the aged) now work" (Brody 1981: 471) - were mentioned, but not their coincidence. Furthermore, since many studies focus on just a few cases (or even a single one) in extremely burdensome situations (for example, Cisholm 1999), it is unknown whether the sandwich situation necessarily is related negatively to well-being and life satisfaction. In this literature, two assumptions are widespread: firstly, that having living parents, children, and participating in the labour force typically coincide, and, sec- 
ondly, that the resulting "role-overload" (Brody 1981: 477) places a significant burden on the middle generation within the family.

Both assumptions can be addressed empirically using quantitative data. Such studies, however, report various and often contradictory results. For example, between one and 80 percent of a population were identified as being sandwiched adults, and with respect to the consequences of being sandwiched, many survey studies do not confirm what the qualitative studies mentioned above suggest - a generally negative relationship to well-being (Spitze et al. 1994; Loomis \& Booth 1995; Penning 1998; Ward \& Spitze 1998; AARP 2001). Therefore, the sandwich phenomenon is sometimes described as a modern "myth" (for example, Loomis \& Booth 1995; Rosenthal et al. 1996; Hölr \& Kytir 1998; Höpflinger \& Baumgärtner 1999; Putney \& Bengtson 2001). A more careful consideration of the research reveals a variety of definitions and concepts that account for these different empirical findings.

Soldo (1996), for example, has analyzed generational constellations with the National Survey of Families and Households in the USA. She reports 80 percent of the 40 to 49 -year-olds to have living parents or parents-in-law and living children. Such a definition of the sandwich situation takes into account neither the exchange of support - e.g., whether the sandwiched adult provides help to parents or children - nor their labour force status. However, since both their parents and their children may also be a source of help to the 40 to 49 -year-olds - a well documented fact in the recent literature on private intergenerational relations (cf. Kohli \& Künemund 2005 for an overview with German data) - the causal relationship of such a sandwich situation and well-being of the sandwich generation is highly questionable.

Rosenthal et al. (1996: S282), using the General Social Survey of Canada, conclude that "being "caught in the middle" is not a typical experience". Only six percent of the women aged 45 to 49 with children are caring for an own parent and participating in the labour force at the same time. But since these authors only take into account own parents and ignore parents-in-law, grandparents, grandparents-in-law, and grandchildren who may also be taken care of, this percentage may as well be 
much higher. ${ }^{2}$ At the same time, the existence of children is used as an indicator of being sandwiched, regardless of their age, or whether they are in need of help and burdensome, or helpful and a source of wellbeing: even in the case of parent care, children may be of help (cf. Raphael \& Schlesinger 1994). Finally, the various definitions of labour force participation, support, and personal care itself may also play a significant role. From this example it is quite obvious why the percentages reported in the literature differ so much.

The international literature on the sandwich phenomenon confirms that these factors are highly relevant for explaining variations in the empirical findings. For example, Dautzenberg et al. (1998) report that from 100 women aged 40 to 54 in the Netherlands 29 have children in their households and support an aged parent or parent-in-law, and 13 additionally participate in the labour force. However, their support variable includes emotional support, which most probably explains these comparably high percentages. Taking into account only full-time labour force participation and support for parents that takes place at least three times a week, they end up with one percent of the women aged 40 to 54 in the sandwich situation.

For Austria, Hörl \& Kytir (1998) report that 50 percent of women aged 40 to 44 that participate in the labour force and have living relatives of both an older and a younger generation, but they are not able to identify any type of support or care in their census data. Wherever data on care activities is available, the percentages tend to be much lower. For example, Höpflinger \& Baumgärtner (1999) - also using census data - find only two percent of women aged 40 to 49 who provide care and have children in their households in Switzerland. In the UK, Evandrou et al. (2002) report that three percent of those women aged 45 to 59 are paid workers, care givers, and mothers at the same time. Interestingly, these authors count only children that are either sick or disabled, unemployed, divorced, separated, widowed, or children 25 years and older that are liv-

Already Brody (1981: 472) has conceptualized the "women in the middle" to "...occupy either the second or the third lineal position in a four generation family". 
ing at home but do not contribute to the household income. On the one hand, this approach evidently results in lower percentages than simply counting any child. On the other hand, in this study the definition of care is not restricted to the parents or parents-in-law, so that caring for the spouse (or neighbours) is included and may result in a higher percentage. Since these authors do address multiple roles in midlife, not the sandwich generation in its strict sense, this strategy is justified. But again it becomes clear, that the results of all these studies are hardly comparable because of very different definitions of the phenomenon.

The variation of these findings may, in general, also reflect limitations in the available data used in the respective studies - well known limitations of secondary analysis. Some studies do not cover information on all relevant relationships and therefore miss out, for example, parentsin-law, grandparents, or grandchildren; others lack information on caring activities or labour force participation. Also, the definitions of what relevant relationships and relevant activities are often depends on the available data, not on theoretical assumptions about the sandwich generation. This is evident, for example, when some authors argue that children relevant for the sandwich phenomena must have children on their own - e.g., grandchildren from the perspective of the sandwiched adult - (for example, Hörl \& Kytir 1999), while others are satisfied with the requirement of adult children for the definition of being sandwiched (for example, Raphael \& Schlesinger 1994), or a child of any age living in the same household (for example, Dautzenberg et al. 1998).

Before further complicating this picture with data from Germany, it seems therefore appropriate to distinguish different levels of the sandwich phenomenon. Four structural definitions of the sandwich generation with different boundaries will be considered:

- A broad definition only takes into account the generational constellation, e.g. the existence of kin of both older and younger generations, including relatives of a partner (e.g., parents-in-law, grandparents-inlaw, children of the partner etc.);

- a narrower definition that additionally takes into account personal care for a parent or parent-in-law;

- a definition that additionally takes into account children in the household or caring for grandchildren; 
- a restrictive definition that additionally takes into account labour force participation.

These definitions will be used to exemplify the contradicting results found in the literature and to identify the level at which a specific burden is typically associated with the sandwich phenomenon. The first definition - implicitly used for example by Soldo (1996) - assumes that having parents and children makes the difference, while the last definition focuses on very special situations of multiple responsibilities.

\section{Data and methods}

The following analyses are based on the second wave of the German Aging Survey, a large representative survey of the German population (restricted to German citizens) born 1917 to 1962 and living in private households (cf. Tesch-Römer et al. 2006). Data were collected in 2002, so that for ease of interpretation we usually refer to the respondents as the 40 to 85 -year-old Germans. The sample $(n=3.084)$ is stratified according to age groups, gender, and East and West Germany; design weights are used to correct for this stratification. Following a personal paper-andpencil interview which includes detailed questions on activities and the family, the respondents received an additional self-administered questionnaire (response rate: 90 percent, $\mathrm{n}=2.787$ ) with - among others - questions on life satisfaction. ${ }^{3}$

On the level of generational constellations, the data permit the inclusion of all relationships from grandparents to great-grandchildren, both from the respondents and their partners. The sandwich situation will therefore not be reduced to own parents and children, which should result in somewhat higher percentages of sandwiched adults compared to the studies reviewed above. The data also provide detailed information

3 The questionnaires are available in the internet (see www.fall-berlin.de for the first and www.dza.de for the second wave of the German Aging Survey). Data are available to researchers at the Central Archive for Empirical Social Research at the University of Cologne (wave 1: Study No. 3264; wave 2: No. 4304). 
on labour force participation, health care and child care activities. ${ }^{4}$ I will therefore firstly present descriptive data related to the different levels of being sandwiched to provide a more complete picture of the sandwich phenomena. I will then analyze the impact that these sandwich situations have on the well-being of the sandwiched adults. OLS-regressions on psychological scales will be used to analyze this relationship: the "Satisfaction With Life Scale" (SWLS) of Diener et al. (1985), and the "Positive And Negative Affect Schedule“ (PANAS) of Watson et al. (1988). Finally I discuss possible future developments of the sandwich constellation and the possible impact of changes in the welfare system.

\section{Empirical results}

At a first glance, the generational constellations - including relatives of the partner and both two younger and older generations - seem to justify the term sandwich generation as a rather common situation: more than 75 percent of the women aged 40 to 44 have relatives of both younger and older generations (figure 1). However, the proportion of sandwiched adults declines rapidly with age. For example, less than 50 percent in the age group 55 to 59 are sandwiched.

The majority of women aged 40 to 59 may therefore be indeed in a situation with competing demands from both older and younger relatives and the labour market. However, most of the parents of these sandwiched adults will probably not be in need of personal care. On the contrary, these parents may even be of help, for example by providing child care, so that drawing conclusions from these generational constellations with respect to a specific burden or role-overload of the sandwich

Roughly translated, the question on health care was "Inside or outside your household, are there persons to whom you provide personal care or help due to health problems?" (cf. questions 323 to 326 in the questionnaire). As a consequence, in the following analyses the term "health care" is used in a very broad sense - it is not restricted to hands-on-care, but may include other types of support in case of health problems, for example housekeeping or shopping activities. 
generation seems highly inappropriate using this broad level of definition. In a second step I therefore concentrate on three groups of women: Those who provide care for a parent or parent-in-law (or grandparent or grandparent-in-law), those who additionally provide care for grandchildren or have children at home, and those who additionally participate in the labour force. All this information was used in a conservative manner, e.g. one hour of labour force participation as well as irregular paid work and one hour of personal care given a month were regarded as being sufficient to indicate the respective activity, and having children at home (regardless of age and marital status etc.) or caring for grandchildren indicate demands from the children's generation.

Figure 1. Sandwich constellations of women (percentages by age group)

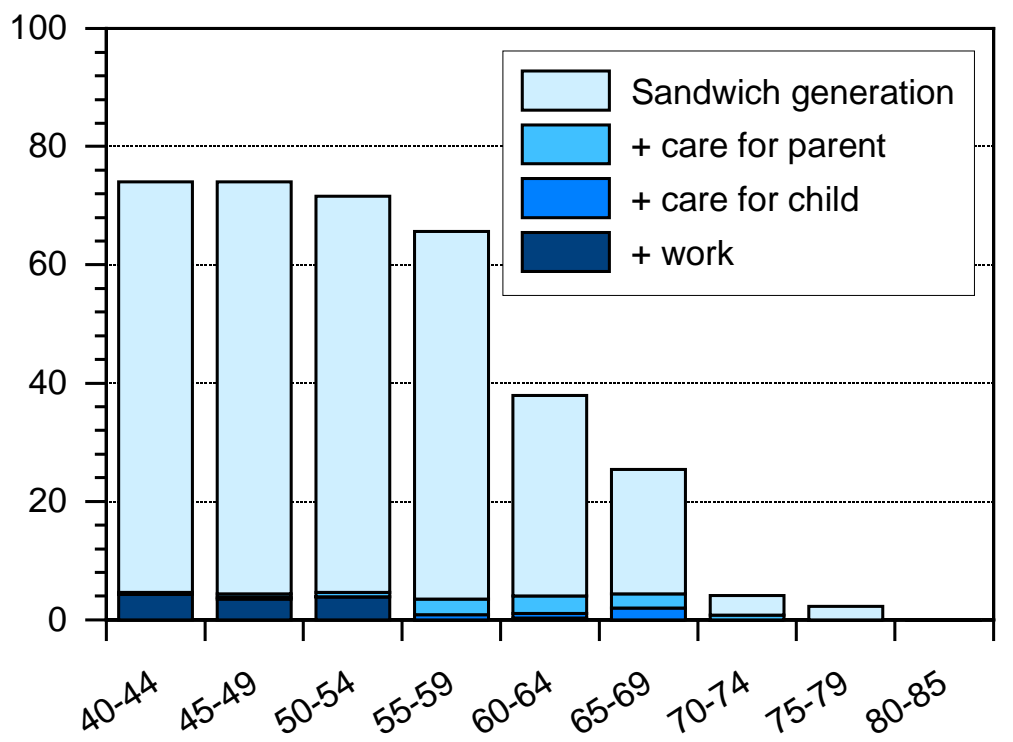

Age group

Source: German Aging Survey $2002(\mathrm{n}=1.536)$. 
These definitions of the sandwich generation provide a completely different picture. Only three percent of the women aged 40 to 44 , eight percent of those aged 45 to 49 , and three percent of the women age 50 to 54 are caring for an elderly family member, have children at home or care for grandchildren, and participate in the labour force at least one hour a month. The strict definition of the sandwich generation leads to a minority of 5 percent of sandwiched women in the age group 40 to 54 . And this percentage would be even lower if, for example, being sandwiched would be conditional on at least 20 hours of paid work a week, or if children that are burdensome could be distinguished from those who are helpful.

The narrower definitions of the sandwich generation also result in fairly low proportions. Ignoring the labour force participation and also the existence of children, the fact of caring for an elderly family member peeks at the age 45 to 59 with about 12 percent. Any definition of a sandwich generation that includes (grand-)parent care - including (grand-)parents-in-law - will result in proportions lower than that.

We may therefore conclude that the term "women in the middle" aptly describes the generational constellation in the middle age group. However, it is not very convincing to infer a specific burden from this constellation. Although feelings of responsibility and concern about family members may be a widespread phenomenon from a psychological point of view, taking into account activities, a multiple burden - what is the common connotation of the terms "sandwich generation" and "caught in the middle" - seems to be a rather rare experience, not a typical situation of the whole middle generation.

Although men are less often involved in parent care, the generational constellation of being sandwiched is even more widespread among men (figure 2). This is mainly an effect of the age difference within couples women typically are younger than their partners, who in turn are more likely to have parents-in-law. The higher labour force participation rates of men also result in a relatively high percentage of sandwiched men in the strict sense: 4 percent of the men aged 40 to 54 care for an older relative, are working, and care for children or have children at home (using the same conservative definitions). The differences between these two figures make clear that women face competing demands from both older 
and younger generations much more often, but - as Brody (1990: 4) has argued - the term "women in the middle" may also apply to men: it is best understood as "a metaphor for all family members who find themselves in that position - the husbands and wives of the disabled elderly, their sons and daughters".

Figure 2. Sandwich constellations of men (percentages by age group)

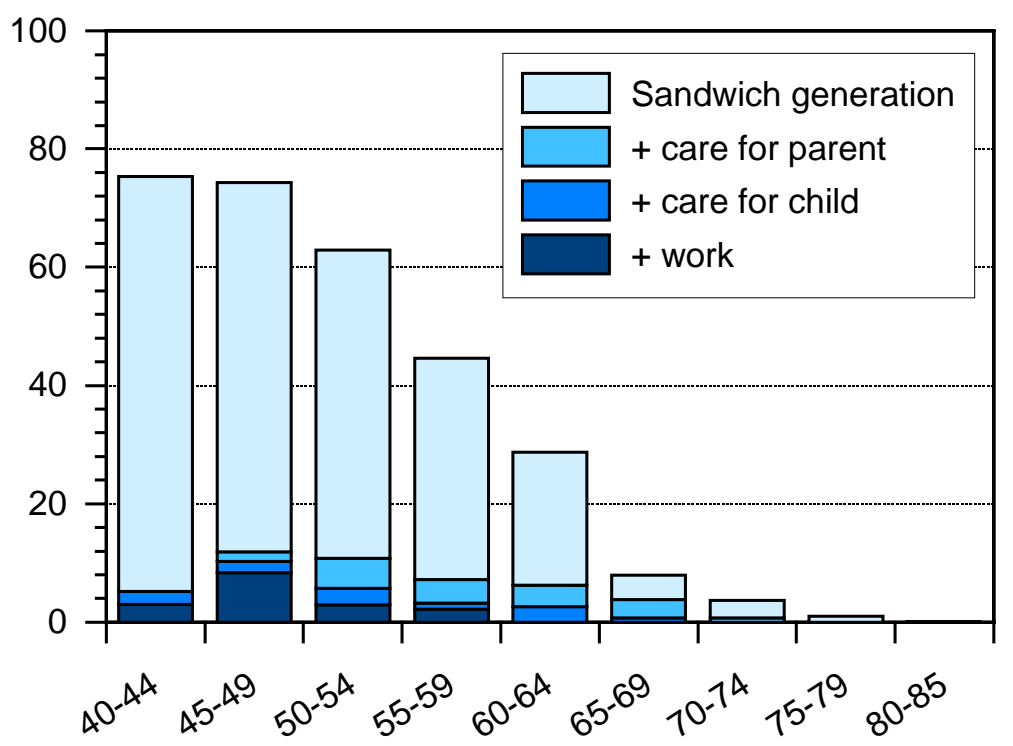

Age group

Source: German Aging Survey $2002(\mathrm{n}=1.541)$.

Another question is whether these sandwich constellations - even if rare in the cross-sectional view - do have an important impact on life satisfaction or the frequency of positive and negative affect. Controlling for 
age, region, health, equivalent income, and the partner constellation, ${ }^{5}$ none of the definitions of the sandwich generation has a significant effect on life satisfaction or positive and negative affect (cf. table 1). For example, health, having a partner, and income are positively associated with life satisfaction. But having both older and younger family members does not significantly reduce life satisfaction, which should be the case if negative feelings of responsibility and concern are typically associated with having (grand-)parents and (grand-)children at the same time. Caring for an elderly family member and having children at home (or taking care of grandchildren), and even having all these responsibilities and additionally participating in the labour force does not decrease satisfaction with life. ${ }^{6}$ Positive affect is associated with income and - only for men - having a partner, but again none of the definitions of the sandwich generation reduces the frequency of positive affect. By contrast, we find a positive effect among women for both the generational constellation and the participation in the labour force, which indicates that children might be a relevant source of help and possible buffering effects of work. Finally, negative affects are solely associated with health problems; the sandwich constellations do not alter the picture.

Age and region (as well as sex) are sample stratification variables. The other variables were held constant because of their well-known strong impact on well-being and affect and their possibly unequal distribution among the groups of interest (for example, those without a partner are less likely to report high levels of well-being and less likely to be sandwiched). If the assumption of a specific burden of the sandwich generation is correct, the respondents in one of the sandwiched situations (at least the "women in the middle" that care for children and parents and at the same time participate in the labour force) should show lower levels of well-being, less frequent positive affect, or more frequent negative affect.

6 Although the empirical evidence is somewhat mixed, quitting labour force participation does not seem to be a general pattern to reduce the burden of the sandwich situation (cf. Moen et al. 1994; Künemund 2000). This becomes also evident from figure 2: even excluding the labour force participation from the definition of being sandwiched, this is a rare situation, not a common experience of a whole generation. 
These findings are also supported by analyses of the first wave of the German Aging Survey. For example, only a minority of 1.4 percent of the women aged 40 to 54 indicate an overburden due to health care activities

Table 1. Satisfaction with life and positive and negative affect (OLSregressions)

\begin{tabular}{|c|c|c|c|c|c|c|}
\hline & \multicolumn{2}{|c|}{ SWLS } & \multicolumn{2}{|c|}{ PANAS pos. } & \multicolumn{2}{|c|}{ PANAS neg. } \\
\hline & Women & Men & Women & Men & Women & Men \\
\hline East Germany & $-.09^{*}$ & -.05 & -.01 & -.02 & -.05 & -.09 \\
\hline Age $>54$ years & .02 & .07 & -.01 & -.01 & $-.13^{* *}$ & -.07 \\
\hline Health impairment & $-.11^{* *}$ & $-.21^{* * *}$ & -.08 & $-.09 *$ & $.16^{* * *}$ & $.20^{* * *}$ \\
\hline Equivalent income & $.21^{* * *}$ & $.21^{* * *}$ & $.24^{\star * *}$ & $.24^{* * *}$ & -.02 & -.05 \\
\hline Partner existent & $.16^{* * *}$ & $.30^{* * *}$ & -.07 & $.14^{* *}$ & -.03 & -.06 \\
\hline Sandwich-Defintions: & & & & & & \\
\hline "Broad" & .06 & -.04 & $.11^{*}$ & $.10^{*}$ & .01 & -.01 \\
\hline "Narrow" 1 & .03 & .03 & $.10^{*}$ & .01 & -.07 & -.05 \\
\hline "Narrow" 2 & .05 & .01 & .01 & .01 & -.08 & -.04 \\
\hline "Strict" & .03 & .01 & $.10^{*}$ & .06 & .02 & -.01 \\
\hline Constant & $11.5^{* *}$ & $10.0^{* *}$ & $23.6^{* *}$ & $20.9^{* *}$ & $11.9^{* *}$ & $11.5^{* \star}$ \\
\hline $\mathrm{R}^{2}$ (corrected) & .10 & .19 & .07 & .09 & .04 & .05 \\
\hline $\mathrm{N}$ & 520 & 516 & 526 & 518 & 525 & 517 \\
\hline
\end{tabular}

Source: German Aging Survey 2002 (40-59 year-olds); standardised coefficients except for constant; ${ }^{*}: \mathrm{p}<.05 ;{ }^{* *}: \mathrm{p}<.01 ;{ }^{* * *}: \mathrm{p}<.001$.

(that in this case also includes caring for a partner or any other relationship, e.g. regardless of the sandwich position) and demands from work and family in the questionnaire (cf. Künemund 2002).

\section{Discussion and conclusions}

Altogether, a restrictive definition of the sandwich generation indicates that this is a rather rare phenomenon, and there is no indication that the sandwich situation is necessarily associated with a specific burden as far 
as it can be measured with these psychological scales. A plausible explanation is the fact that younger family members may also be a source of help in providing care for the elderly, not necessarily an additional burden. Without any doubt, the competing demands from work and family, especially with respect to elder care, may induce a heavy burden on women and men. Many qualitative studies have illustrated that fact very well. But although this situation may sometimes be worsened by dependent children, there seems to be no systematic deterioration of this situation due to the existence of younger generations within the family, e.g., the sandwich phenomenon. In light of these results, the metaphor of the sandwich generation is not a very useful description, and the connotation of a specific overburden due to the existence of both older and younger generations has to be rejected. It may be argued that the percentage of individuals in the sandwich situation may be higher in a life course perspective, e.g. that more men and women are sandwiched in the strict sense at least for a short period of time. The multivariate analyses, however, make clear that, even so, the sandwich situation is not generally one of role-overload or overburden.

Will such situations become more relevant in the near future, as has been suggested already by Brody (1981)? Are the daughters of the baby boom cohorts disadvantaged because of the different size of their own and their parent's cohorts, additional reductions in welfare state spending for elderly people, and changes in marriage patterns? The increase in the number and the proportion of elderly people and the decrease of the number of daughters and daughters-in-law, along with rising labour force participation rates of women, and the given financial problems of the welfare state make such an assumption quite plausible. But the picture is much more complex than that. ${ }^{7}$

A first factor to think of is life expectancy. Assuming we will face a compression of morbidity in old age - not an expansion -, the average

For a more detailed account it would be necessary to work with concrete data on life expectancy, marital status, fertility etc. for different birth cohorts. Here I will speculate simply with a few examples to provide some ideas of possible future developments. 
age at which care for the parents becomes necessary will increase in the future. It is plausible to assume that a growing number of women that care for an aged parent will already be in their retirement age. Competing demands from work and the family may therefore become less relevant in the future. Of course, rising retirement ages may offset this effect to some degree. And since the average distance in years between the generations within a family increases, the average age at which care of a parent becomes most likely may change less compared to the increase in life expectancy.

However, the historical process of the rising average age of mothers at the time of child bearing also has an impact with respect to child care and babysitting activities, as is the case with the decreasing birth rates. For example, increasing childlessness and a decrease in the average number of children decreases the relevance of the sandwich situation simply because there are fewer children. And at the age of 50 to 60 the children of women who care for an elderly parent are most likely within an age range where they can stand on their own feet, but still do not have children on their own. Speculating about the future of the sandwich generation in that direction may therefore also lead to an increasing insignificance of the concept.

Another relevant factor is marriage behaviour and marital status in general. Within the next 20 years, there will be - at least in Germany - a less skewed distribution of men and women compared to the situation of today. Due to the Second World War there are very high proportions of widows and elderly women living alone in Germany, more than one would expect as a consequence of the different life expectancies and the usual age difference within couples. This will change in a few years so that the need for elder care from children is reduced as far as the proportion of elderly people with a living partner increases. Later cohorts are believed to have partners less often, but whether today's singles stay singles into old age is still an open question. However, fewer partners imply fewer parents-in-law to care for, so that the consequences for the sandwich situation are not necessarily that negative.

It is also necessary to think about changing gender roles. Today, elder care is said to be "female" because daughters and daughters-in-law care for their mothers and mothers-in-law. Men are believed to only fill 
the gap when there are no women at hand (cf. for example Qureshi 1990). However, there are some caring men, ${ }^{8}$ and hopefully their proportion will increase in the future. The chances may be improved, compared to the situation today, where the elderly themselves have considerablely strict expectations regarding the type of help to be provided from sons and daughters. When both men and women are about equally involved in gainful work, a discussion about sharing the burden of elder care seems inevitable.

In any case, a reduction in welfare state spending for the aged - pensions or services - will most likely imply heavier responsibilities for the family. This will be true especially for families with less economic resources who cannot simply buy missing services in the market. We have argued that the quality of private intergenerational relationships and family solidarity may therefore be worsened in the near future (cf. Künemund \& Rein 1999). And to the extent that the sons and daughters of the baby boom cohorts maintain traditional gender roles, the result is most probably a heavier burden for women. We therefore may have a threefold interaction of social class, cohort, and gender that deserves further research. The metaphor of the sandwich generation, however, should be treated extremely cautiously: Being sandwiched - having parents and children - is not necessarily a situation of role-overload and overburden.

\section{Acknowledgements}

I am grateful to Martin Kohli, Claudia Vogel, and the anonymous reviewers for their comments and suggestions.

8 Cf. Spitze \& Logan (1990); Nichols \& Junk (1997); Johnson \& Lo Sasso (2000); Künemund (2000); Spillman \& Pezzin (2000); Evandrou \& Glaser (2002). Furthermore, men who care for a parent have the same average number of sisters and are as often married as all men, which clearly contradicts the hypothesis that men only fill the gap when nobody else is available (cf. Künemund 2000). 


\section{References}

American Association of Retired Persons (AARP) (2001). In the middle: A report on multicultural boomers coping with family and aging issues. Washington: AARP.

Brody, E. M. (1981). "Women in the middle" and family help to older people. The Gerontologist 21 (5): 471-480.

Brody, E. M. (1990). Women in the middle: Their parent-care years. New York: Springer.

Cantor, M. H. (1991). Family and community: Changing roles in an aging society. The Gerontologist 31 (3): 337-346.

Chisholm, J. F. (1999). The Sandwich Generation. Journal of Social Distress and the Homeless 8(3): 177-191.

Dautzenberg, M. G. H., Diederiks, J. P. M., Philipsen, H. \& Stevens, F. C. J. (1998). Women of a middle generation and parent care. International Journal of Aging and Human Development 47(4): 241-262.

Diener, E., Emmons, R. A., Larsen, R. J. \& Griffin, S. (1985). The satisfaction with life scale. Journal of Personality Assessment 49 (1): 71-75.

Evandrou, M. \& Glaser, K. (2002). Changing economic and social roles: The experience of four cohorts of mid-life individuals in Britain. Population Trends 110: 19-30.

Evandrou, M., Glaser, K. \& Henz, U. (2002). Multiple role occupancy in midlife: Balancing work and family life in Britain. The Gerontologist 42(6): 781-789.

Höpflinger, F. \& Baumgärtner, D. (1999). "Sandwich-Generation": Metapher oder soziale Realität? ["Sandwich-generation": Metaphor or social reality?]. Zeitschrift für Familienforschung 11(3): 102-111.

Hörl, J. \& Kytir, J. (1998). Die "Sandwich-Generation": Soziale Realität oder gerontologischer Mythos? Basisdaten zur Generationenstruktur der Frauen mittleren Alters in Österreich [The "sandwich-generation": social reality or gerontological myth?] . Kölner Zeitschrift für Soziologie und Sozialpsychologie 50(4): 730-741.

Johnson, R. W. \& LoSasso, A. T. (2000). The trade-off between hours of paid employment and time assistance to elderly parents at midlife. Washington: The Urban Institute (Ms.).

Kohli, M. \& Künemund, H. (2005). The midlife generation in the family: Patterns of exchange and support. In Sherry L. Willis \& Mike Martin 
(eds.), Middle Adulthood: A Lifespan Perspective (pp. 35-61). Newbury Park: Sage.

Künemund, H. (2000). Pflegetätigkeiten in der zweiten Lebenshälfte Verbreitung und Perspektiven [Care giving in the second half of life]. In Clemens, W. \& Backes, G. (Hrsg.), Lebenslagen im Alter. Gesellschaftliche Bedingungen und Grenzen (pp. 215-229). Opladen: Leske + Budrich.

Künemund, H. (2002). Die "Sandwich-Generation" - typische Belastungskonstellation oder nur gelegentliche Kumulation von Erwerbstätigkeit, Pflege und Kinderbetreuung? [The "sandwich-generation" - A typical burden or an occasional coincidence of work, care, and babysitting?]. Zeitschrift für Soziologie der Erziehung und Sozialisation 22(4): 344-361.

Künemund, H. \& Rein, M. (1999). There is more to receiving than needing: Theoretical arguments and empirical explorations of crowding in and crowding out. Ageing and Society 19 (1): 93-121.

Loomis, L. S. \& Booth, A. (1995). Multigenerational caregiving and wellbeing: The myth of the beleaguered sandwich generation. Journal of Family Issues 16(2): 131-148.

Moen, P., Robertson, J. \& Fields, V. (1994). Women's work and caregiving roles: A life course approach. Journal of Gerontology: Social Sciences 49(4): S176-S186.

Nichols, L. S. \& Junk, V. W. (1997). The sandwich generation: Dependency, proximity, and task assistance needs of parents. Journal of Family and Economic Issues 18 (3): 299-326.

Penning, M. J. (1998). In the middle: Parental caregiving in the context of other roles. Journal of Gerontology: Social Sciences 53B (4): S188- S197.

Putney, N. M. \& Bengtson, V. L. (2001). Families, intergenerational relations, and kinkeeping in midlife. In Lachman, M. E. (ed.), Handbook of midlife development (pp. 528-570). New York: Wiley.

Qureshi, H. (1990). A research note on the hierarchy of obligations among informal carers - a response to Finch and Mason. Ageing and Society 10(2): 455-458.

Raphael, D. \& Schlesinger, B. (1994). Women in the sandwich generation: Do adult children living at home help? Journal of Women and Aging 6(1/2): 21-45. 
Roots, C. R. (1998). The sandwich generation: Adult children caring for aging parents. New York: Garland Publications.

Rosenthal, C. J., Martin-Matthews, A. \& Matthews, S. H. (1996). Caught in the middle? Occupancy in multiple roles and help to parents in a national probability sample of Canadian adults. Journal of Gerontology: Social Sciences 51B(6): S274-S283.

Soldo, B. J. (1996). Cross-pressures on middle-aged adults: A broader view. Journal of Gerontology: Social Sciences 51B (6): S271-S273.

Spillman, B. C. \& Pezzin, L. E. (2000). Potential and active family caregivers: Changing networks and the "sandwich generation". Milbank Quarterly 78(3): 347-374.

Spitze, G. \& Logan, J. R. (1990). More evidence on women (and men) in the middle. Research on Aging 12 (2): 182-198.

Spitze, G., Logan, J. R., Genevieve J. \& Eunju Lee (1994). Middle generation roles and the well-being of men and women. Journal of Gerontology: Social Sciences 49(3): S107-S116.

Tesch-Römer, C., Engstler, H. \& Wurm, S. (Hrsg.) (2006). Altwerden in Deutschland. Sozialer Wandel und individuelle Entwicklung in der zweiten Lebenshälfte [Ageing in Germany. Social change and individual development in the second half of life]. Wiesbaden: VS Verlag für Sozialwissenschaften.

Ward, R. A. \& Spitze, G. (1998). Sandwiched Marriages: The implications of child and parent relations for marital quality at midlife. Social Forces 77(2): 647-666.

Watson, D., Clark, L. A. \& Tellegen, A. (1988). Development and validation of brief measures of positive and negative affect: The PANAS scales. Journal of Personality and Social Psychology 54 (6): 1063-1070.

Zal, M. H. (1992). The sandwich generation: Caught between growing children and aging parents. New York: Plenum Press. 